\title{
Meditation May Alter Medication Sleep Disorder and Mental Illness
}

\author{
Ven Sumedh Thero* \\ Department of Sleep disorder and Mental Health, USA
}

*Corresponding author: Ven Sumedh Thero, Department of Sleep disorder and Mental Health, USA.

Received Date: August 12, 2019

Published Date: August 30, 2019

\begin{abstract}
People suffer from depression, discouragement, hatred, resentment, fear, and anger. And those feelings give birth to more and more violence. Road rage leads to traffic injuries and deaths. The feelings were certain kinds of self-respect and self-esteem, self-worth, and self-accomplishment, as well as romantic love and friendship. Those persons who tend to have strong emotional responses and to take longer times to recover from them are more likely to suffer from stress-related conditions and produce much amount of Cortisol is a steroid hormone, in the glucocorticoid class of hormones. A persons disposed to anxiety and depression would benefit greatly if they would meditate daily on compassion, for themselves and for all sentient beings. Buddhism has placed a greater urgency upon inner reflection. With the awakening to the interdependent reality, selfish compulsive responses will be replaced by loving-kindness, compassion, sympathetic joy, and equanimity. It is the responsibility of the institutions to inculcate better attitude and behavior through holistic education process so that quality students can be supplies to the forthcoming generations.
\end{abstract}

Keywords: Anxiety; Cortisol; Depression; Happiness; Loving-kindness

\section{Introduction}

Neurological disorders are medically defined as disorders that affect the brain as well as the nerves found throughout the human body and the spinal cord. These three parts of the body work together and are referred to as the central nervous system that control everything in the body. Neurology is the medical science that deals with the nervous system and disorders that affect it. Examples of symptoms include paralysis, muscle weakness, poor coordination, loss of sensation, seizures, confusion, pain and altered levels of consciousness. The specific causes of neurological problems vary, but can include genetic disorders, congenital abnormalities or disorders, infections, lifestyle or environmental health problems including malnutrition, and brain injury, spinal cord injury or nerve injury. There are many recognized neurological disorders, some relatively common, but many rare. They may be assessed by neurological examination and studied and treated within the specialties of neurology and clinical neuropsychology. Mental disorders, on the other hand, are "psychiatric illnesses" or diseases which appear primarily as abnormalities of thought, feeling or behavior, producing either distress or impairment of function. Conditions that are classed as mental disorders, or learning disabilities and forms of Intellectual disability, are not themselves usually dealt with as neurological disorders. Neurological disorders can be categorized according to the primary location affected, the primary type of dysfunction involved, or the primary type of cause. The broadest division is between central nervous system disorders and peripheral nervous system disorders. Neurological disorders can affect an entire neurological pathway or a single neuron. Even a small disturbance to a neuron's structural pathway can result in dysfunction.

According to the University of California, San Francisco, there are more than 600 neurological disorders that strike millions of Americans each year. These diseases and disorders inflict great pain and suffering on millions of patients and their families and cost the U.S. economy billions of dollars annually. Social Security approves disability benefits for serious cases of epilepsy, cerebral palsy, Parkinson's disease, multiple sclerosis, ALS, and other nervebased diseases. Neurological disorders are diseases of the central and peripheral nervous system. In other words, the brain, spinal cord, cranial nerves, peripheral nerves, nerve roots, autonomic nervous system, neuromuscular junction, and muscles. These disorders include epilepsy, Alzheimer disease and other dementias, cerebrovascular diseases including stroke, migraine and other 
headache disorders, multiple sclerosis, Parkinson's disease, neuroinfections, brain tumours, traumatic disorders of the nervous system due to head trauma, and neurological disorders as a result of malnutrition. Many bacterial (i.e. Mycobacterial tuberculosis, Neisseria meningitides), viral (i.e. Human Immunodeficiency Virus (HIV), Enteroviruses, West Nile Virus, Zika), fungal (i.e. Cryptococcus, Aspergillus), and parasitic (i.e. malaria, Chagas) infections can affect the nervous system. Neurological symptoms may occur due to the infection itself, or due to an immune response. Hundreds of millions of people worldwide are affected by neurological disorders. More than 6 million people die because of stroke each year; over $80 \%$ of these deaths take place in lowand middle-income countries. More than 50 million people have epilepsy worldwide. It is estimated that there are globally 47.5 million people with dementia with 7.7 million new cases every year - Alzheimer's disease is the most common cause of dementia and may contribute to $60-70 \%$ of cases. The prevalence of migraine is more than $10 \%$ worldwide.

\section{Disorder}

Eating disorders involve disproportionate concern in matters of food and weight Categories of disorder in this area include anorexia nervosa, bulimia nervosa, exercise bulimia or binge eating disorder. Sleep disorders such as insomnia involve disruption to normal sleep patterns, or a feeling of tiredness despite sleep appearing normal. Sexual disorders and gender dysphoria may be diagnosed, including dyspareunia and ego-dystonic homosexuality. Various kinds of paraphilia are considered mental disorders (sexual arousal to objects, situations, or individuals that are considered abnormal or harmful to the person or others). People who are abnormally unable to resist certain urges or impulses that could be harmful to themselves or others, may be classed as having an impulse control disorder, and disorders such as kleptomania (stealing) or pyromania (fire-setting). Various behavioral addictions, such as gambling addiction, may be classed as a disorder. Obsessive-compulsive disorder can sometimes involve an inability to resist certain acts but is classed separately as being primarily an anxiety disorder. The use of drugs (legal or illegal, including alcohol), when it persists despite significant problems related to its use, may be defined as a mental disorder. Dystonia is a neurological movement disorder syndrome in which sustained or repetitive muscle contractions result in twisting and repetitive movements or abnormal fixed postures. The movements may resemble a tremor. Dystonia is often intensified or exacerbated by physical activity, and symptoms may progress into adjacent muscles (Balint, et al.) [1]. The disorder may be hereditary or caused by other factors such as birth-related or other physical trauma, infection, poisoning (e.g., lead poisoning) or reaction to pharmaceutical drugs, particularly neuroleptics. Treatment must be highly customized to the needs of the individual and may include oral medications, chemodenervation botulinum neurotoxin injections, physical therapy, or other supportive therapies, and surgical procedures such as deep brain stimulation (Figure 1).

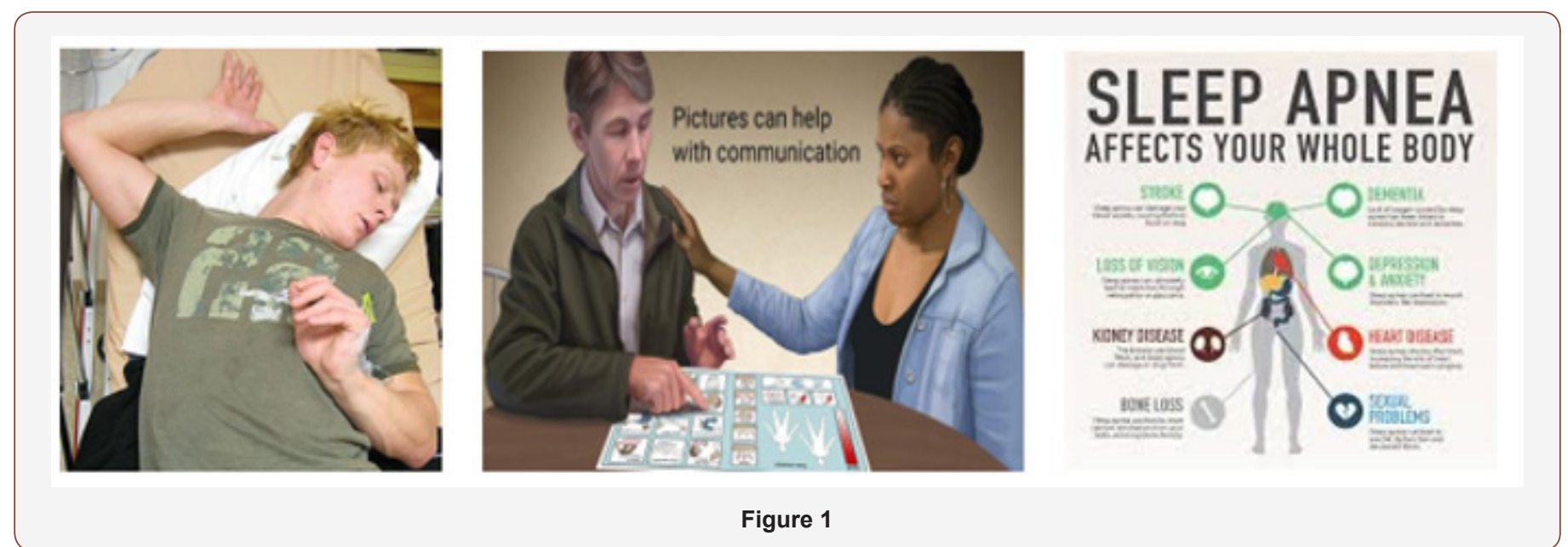

A systematic review found that traumatic childhood experiences (such as family conflict or sexual trauma) significantly increases the risk for a number of sleep disorders in adulthood, including sleep apnea, narcolepsy, and insomnia. It is currently unclear whether or not moderate alcohol consumption increases the risk of obstructive sleep apnea. Alcohol, sedatives and tranquilizers may also promote sleep apnea by relaxing throat muscles. Smokers have sleep apnea at three times the rate of people who have never smoked. Apnea or apnoea is the cessation of breathing. During apnea, there is no movement of the muscles of inhalation, and the volume of the lungs initially remains unchanged. Depending on how blocked the airways are (patency), there may or may not be a flow of gas between the lungs and the environment; gas exchange within the lungs and cellular respiration is not affected. Voluntarily doing this is called holding one's breath. According to one meta-analysis, the two most prevalent sleep disorders among children are confusional arousals and sleep walking (Carter, et al.) [2]. An estimated 17.3\% of kids between 3 and 13 years old experience confusional arousals. About $17 \%$ of children sleep walk, with the disorder being more common among boys than girls. The peak ages of sleep walking are from 8 to 12 years old (Carter, et al.) [2]. A different systematic review offers a high range of prevalence rates of sleep bruxism for children. Between 15.29 and 38.6\% of preschoolers grind their teeth at least one night a week. All but one of the included studies reports decreasing bruxist prevalence as age increased as well as a higher prevalence among boys than girls (Machado) [3]. 
Another systematic review noted $7-16 \%$ of young adults suffer from delayed sleep phase disorder. This disorder reaches peak prevalence when people are in their 20s.[42] Between 20 and 26\% of adolescents report a sleep onset latency of $>30$ minutes. Also,
7-36\% have difficulty initiating sleep. Asian teens tend to have a higher prevalence of all of these adverse sleep outcomes than their North American and European counterparts (Gradisar) [4] (Figure 2).

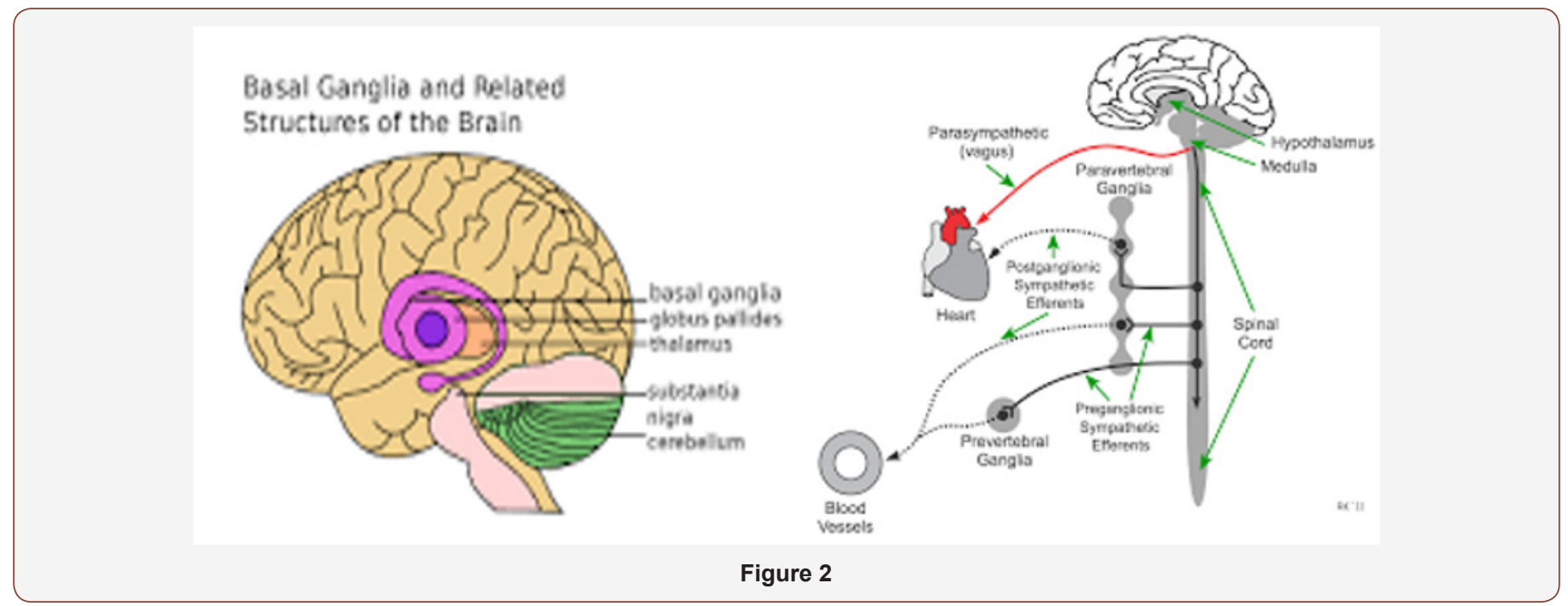

A number of uncommon toxins are capable of causing brain damage centred in the motor control region known as the basal ganglia. Dystonia may be one prominent feature experienced by people with these exposures, but it is extremely uncommon for 'isolated dystonia' to be seen in such patients. In other words, the vast majority of people exposed to toxins (i.e. manganese) have additional neurological problems associated with the dystonia. Possibly the most common feature is such patients is the presence of a Parkinson's Disease-like state. Different societies or cultures, even different individuals in a subculture, can disagree as to what constitutes optimal versus pathological biological and psychological functioning. Research has demonstrated that cultures vary in the relative importance placed on, for example, happiness, autonomy, or social relationships for pleasure. Likewise, the fact that a behavior pattern is valued, accepted, encouraged, or even statistically normative in a culture does not necessarily mean that it is conducive to optimal psychological functioning. People in all cultures find some behaviors bizarre or even incomprehensible. But just what they feel is bizarre or incomprehensible is ambiguous and subjective (Heinimaa) [5]. These differences in determination can become highly contentious. The process by which conditions and difficulties come to be defined and treated as medical conditions and problems, and thus come under the authority of doctors and other health professionals, is known as medicalization or pathologization (Figure 3).

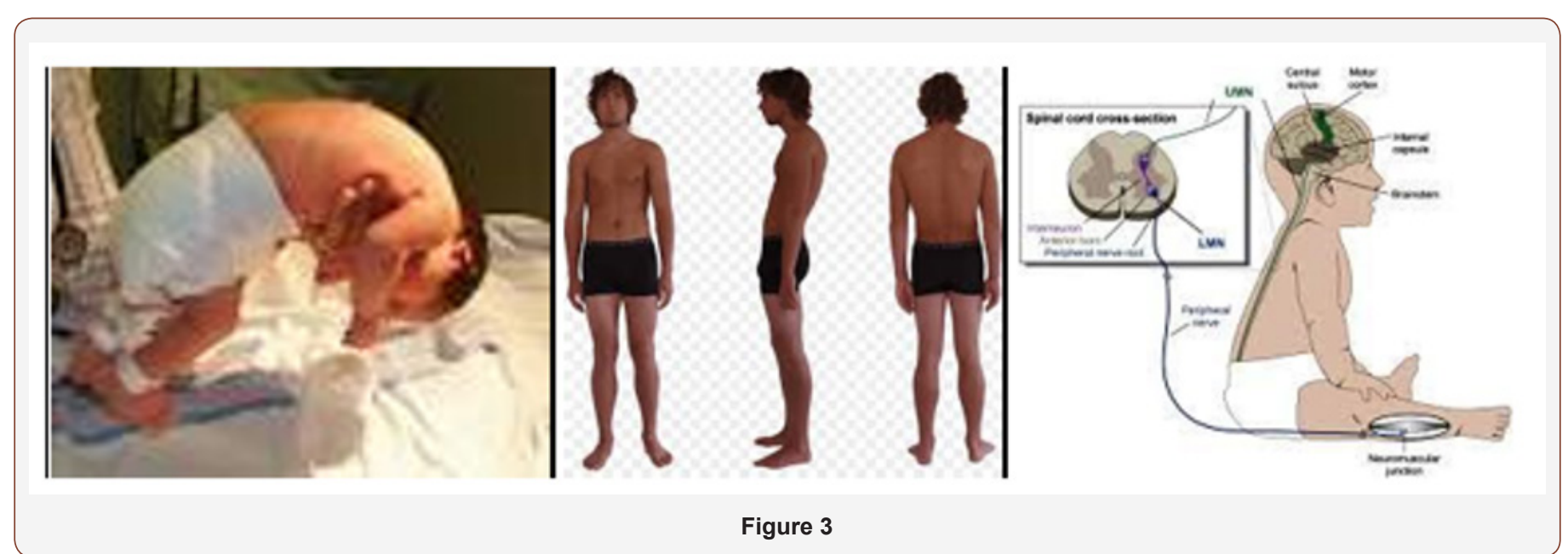

Religious, spiritual, or transpersonal experiences and beliefs meet many criteria of delusional or psychotic disorders (Pierre and Johnson and Friedman) [6,7]. A belief or experience can sometimes be shown to produce distress or disability-the ordinary standard for judging mental disorders. There is a link between religion and schizophrenia (Siddle, et al.) [8] a complex mental disorder characterized by a difficulty in recognizing reality, regulating emotional responses, and thinking in a clear and logical manner. Those with schizophrenia commonly report some type of religious delusion, and religion itself may be a trigger for schizophrenia (Mohr, et al.) [9]. 


\section{Medication}

Melatonin, also known as N-acetyl-5-methoxy tryptamine, is a hormone that is produced by the pineal gland in humans and animals and regulates sleep and wakefulness (Hardeland, etal.) [10]. Melatonin is also produced in plants where it functions as a first line of defense against oxidative stress (Tan, et al.) [11]. Altun and Altun [12] found in animals, melatonin is involved in the entrainment (synchronization) of the circadian rhythms including sleep-wake timing, blood pressure regulation, seasonal reproduction, and many others. Many of its biological effects in animals are produced through activation of melatonin receptors (Boutin, et al.) [13], while others are due to its role as an antioxidant (Hardeland) [14], particularly in the protection of nuclear and mitochondrial DNA (Reiter, et al.) [15]. As a medicine, it is used for the treatment of insomnia; however, scientific evidence is insufficient to demonstrate a benefit in this area. Melatonin is sold over the counter in the United States, Canada and some European countries. In other countries, it may require a prescription or it may be unavailable. Melatonin can cause nausea, next-day grogginess, and irritability (Brent Bauer.) [16]. In the elderly, it can cause reduced blood flow and hypothermia (Zhdanova) [17]. In autoimmune disorders, evidence is conflicting whether melatonin supplementation may ameliorate or exacerbate symptoms due to immunomodulation (Morera, et al. and Terr, et al.) $[18,19]$. Juszczak and Michalska [20] reported that Melatonin can lower follicle-stimulating hormone levels. While in further studies Srinivasan et al. [21] reported that Melatonin's effects on human reproduction remain unclear (Figure 4).

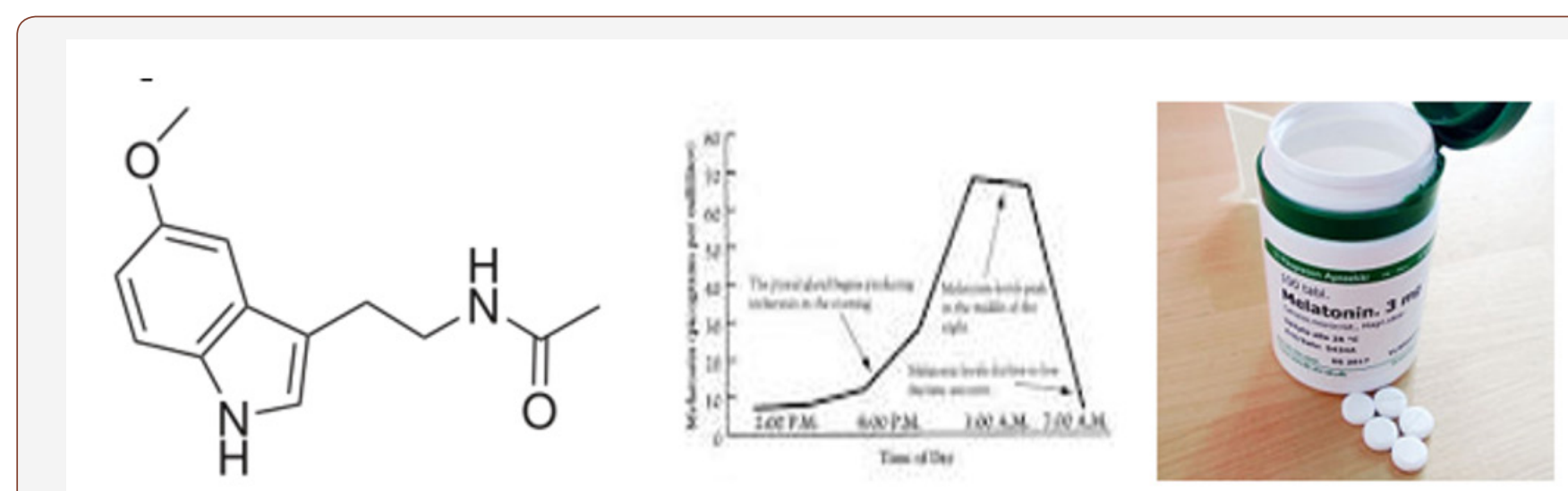

Figure 4

Immunomodulators are those extrinsic or intrinsic substances which regulate or alter the scope, type, duration or competency of the immune response. This paper presents an overview of the mechanisms of immunomodulation and discusses selected chemical and biologic substances which are capable of modifying the immune or biologic response of the organism. The immunopharmacology, including in vivo and in vitro assays, of a novel acridine immunomodulator is discussed. This low molecular weight compound is an immunomodulator and anti-cancer adjuvant, which has been shown to induce high levels of circulating interferon in mice, protect mice against lethal viral infection, stimulate macrophage and NK cell cytotoxicity for tumor cells, partially restore humoral and cellular immune responses in tumor bearing immuno suppressed mice, and augment the cytotoxic T-lymphocyte response to syngeneic tumor cells. Tissue changes, consisting of presence of drug bound to lysosomal membranes, perivascular infiltrates in mouse liver, glomerular hyalinization in mouse kidney, and focal myocardial changes in mice are described. The compound persists intra cellularly for extended periods of time in cells with high lysosomal activity. The tissue changes are interpreted to be a result of overloading of cellular mechanisms for elimination from the cells involved (Lebish and Moraski) [22]. Medications and somatic treatments may provide the most rapid symptomatic relief from some sleep disturbances. Certain disorders like narcolepsy, are best treated with prescription drugs such as modafinil (Voderholzer, et al.) [23]. Others, such as chronic and primary insomnia, may be more amenable to behavioral interventions, with more durable results.

Meditation practices may differ in the modern Buddhist traditions and non-sectarian groups according to the founder but the main objective is to develop insight. Insight is the intuitive light flashing forth and exposing the truth of impermanency, the suffering and the impersonal and unsubstantial nature of all corporeal and mental phenomena of existence. It is Insight-wisdom that is the decisive liberating factor in Buddhism, though it has to be developed along with the two other trainings in morality and concentration. The culmination of Insight practice leads directly to the stages of Holiness. Insight is not the result of a mere intellectual understanding but is won through direct meditative observation of one's own bodily and mental processes. Thus Vipassana is a way of self-transformation through self-observation. It focuses on the deep interconnection between mind and body, which can be experienced directly by disciplined attention to the physical sensations that form the life of the body, and that continuously interconnect and condition the life of the mind. It is this observation-based, selfexploratory journey to the common root of mind and body that dissolves mental impurity, resulting in a balanced mind full of love and compassion. The scientific laws that operate one's thoughts, feelings, judgements and sensations become clear. Through direct experience, the nature of how one grows or regresses, how one 
produces suffering or frees oneself from suffering is understood. Life becomes characterized by increased awareness, non-delusion, self-control and peace.

According to the Buddha's teaching of Dependent Origination, everything, including the psychophysical compound that we call individual, exists only in relation to other beings and things and undergoes constant changes responding and reacting to them. The next section examines the Buddhist perspective on the causes violence and ways to prevent violence and realize peace. The last section explores the potentials Buddhist contributions to the peacemaking efforts and the promotion of a culture of peace in today's world. Believing that the root of violence is located within the mind, Buddhism has placed a greater urgency upon inner reflection. With the awakening to the interdependent reality, selfish compulsive responses will be replaced by loving-kindness, compassion, sympathetic joy, and equanimity (Figure 5).

\section{Before and after meditation ; Prolong age}

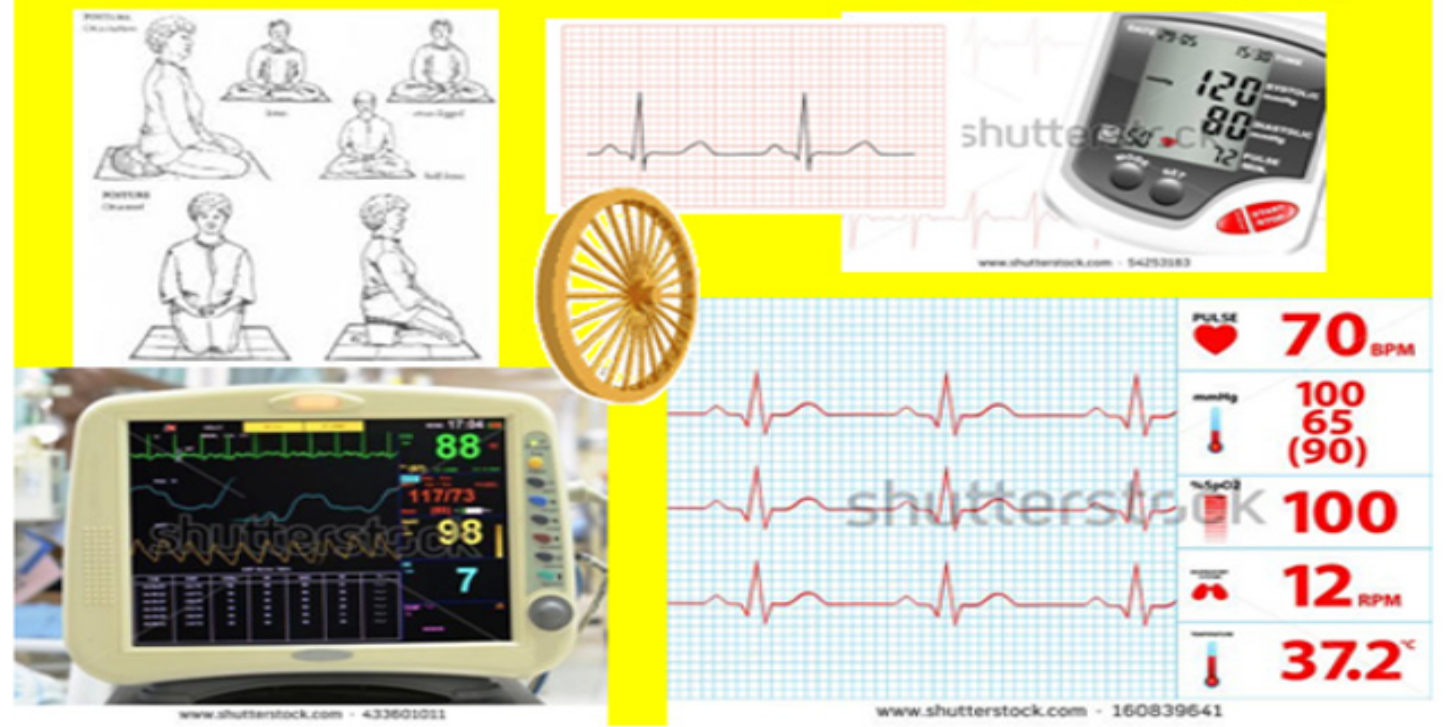

Figure 5

On the behavioral level, one practices peace daily by observing the Five Precepts. To prevent in-group disputes, the Buddha teaches the six principles of cordiality in any community. As for inter-group or international affairs, Buddhist scriptures are rift with stories that teach nonviolent intervention. The Buddhist worldview is surprisingly in accordance with the insights of peace studies in its process oriented paradigm, its insistence on peace by peaceful means, and its holistic framework of peace, which would play a vital role in the efforts of bringing the culture of peace into existence around the world towards transforming Society. Thus Vipassana Meditation Process has high importance to get orient the individuals with better physique, psycho-social state that helps to become good professional with focused managerial aptitude schools. So that institutions can bridge the gap between 'what society wants and what institutions now providing' (Figure 6).

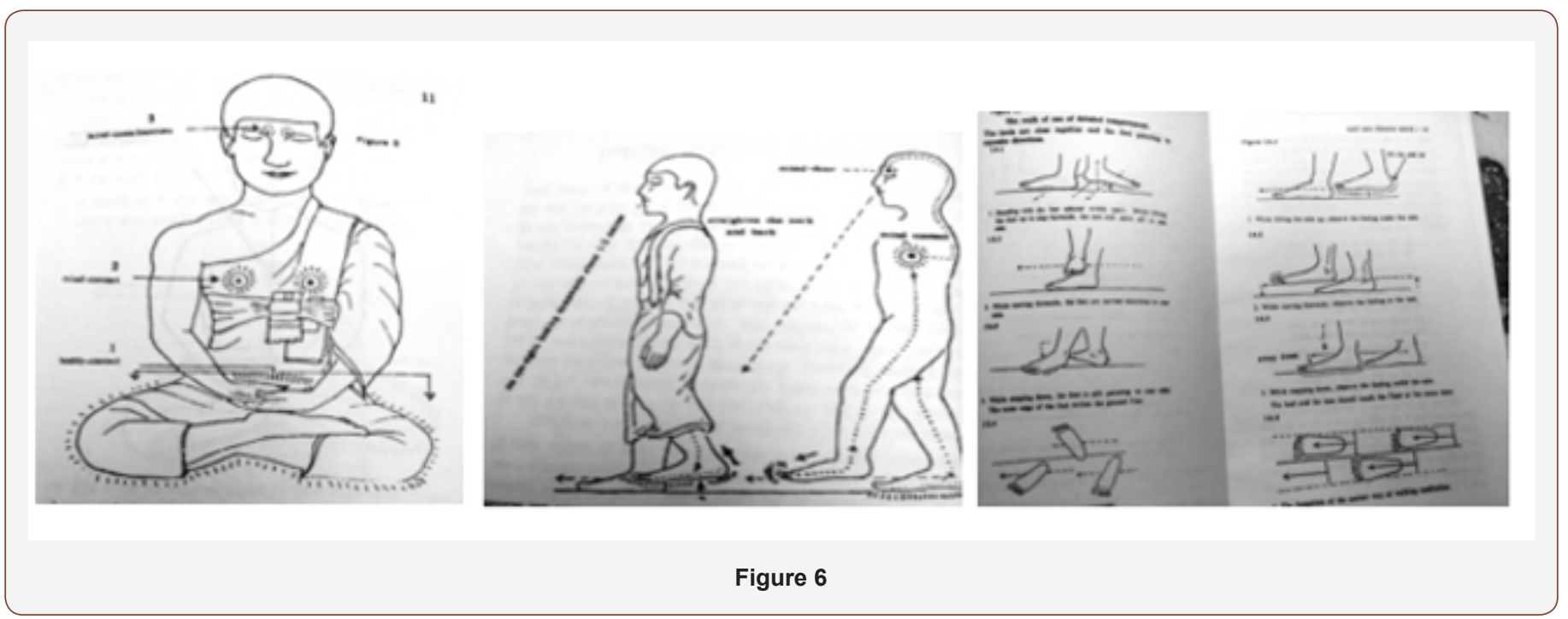


Vipassana is one of India's most ancient meditation techniques. Long lost to humanity, it was rediscovered by Gotama the Buddha more than 2607 years ago. The word Vipassana means seeing things as they really are. It is the process of self- purification by self-observation. One begins by observing the natural breath to concentrate the mind. With a sharpened awareness one proceeds to observe the changing nature of body and mind and experiences the universal truths of impermanence, suffering and egolessness. This truth-realization by direct experience is the process of purification. The entire path (Dhamma) is a universal remedy for universal problems and has nothing to do with any organized religion or sectarianism. For this reason, it can be freely practiced by everyone, at any time, in any place, without conflict due to race, community or religion, and will prove equally beneficial to one and all (Table 1).

Table 1: Physical Advantages of Vipassana.

\begin{tabular}{|c|c|c|c|}
\hline \multirow{2}{*}{ Sl. No. } & Physical Advantage of Vipassana & \multicolumn{2}{|c|}{ Students } \\
\cline { 3 - 4 } & N & $\%$ \\
\hline 2 & $\begin{array}{c}\text { Understand ones own hidden strength } \\
\text { and potential. }\end{array}$ & 27 & 20.3 \\
\hline 3 & $\begin{array}{c}\text { Reduced Anxiety about food (One } \\
\text { meal is enough in one day) }\end{array}$ & 2 & 1.5 \\
\hline 4 & Body becomes more flexible. & 17 & 12.8 \\
\hline 5 & Physical level resistance increased & 2 & 1.5 \\
\hline 6 & Aware of healthy diet & 3 & 2.3 \\
\hline 7 & $\begin{array}{c}\text { Efficiency of digestive system } \\
\text { increased. }\end{array}$ & 3 & 2.3 \\
\hline 8 & Get rid of too much addiction of tea & 2 & 1.5 \\
\hline 9 & having habit & 3 & 2.3 \\
\hline 10 & Feel healthy and fresh & 15 & 11.3 \\
\hline 11 & Reduced body weight & 4 & 3 \\
\hline 12 & Better breathing & 2 & 1.5 \\
\hline 13 & Early wake up and early bed habit & 2 & 1.5 \\
\hline 14 & attained & 8 & 6 \\
\hline 15 & Increased concentration & 15 & 11.3 \\
\hline 16 & Ability to withstand pain & 1 & 0.8 \\
\hline & No back pain & 133 & 10.8 \\
\hline
\end{tabular}

Data presented in Table-1 indicated that majority business management graduates get physical advantages of Vipassana Meditation process, in one way or other. Major benefits includes understanding of hidden potentials (20.3\%), ability to withstand pain (15\%), flexibility of physique, (12.8\%), positive feeling (11.3), increased concentration $(6 \%)$ etc. Students obtained different advantages by undergoing this awareness process. Thus Control over Tension angry frustration, agitation anxiety, and impatience Developed balanced mind Better concentration Make better decision making Objective perception More empathetic, organized, confident, orderly and disciplined.

\section{Acknowledgement}

None.

\section{Conflict of Interest}

No conflict of interest.

\section{References}

1. Balint Bettina, Bhatia Kailash P (2014) Dystonia: an update on phenomenology, classification, pathogenesis and treatment. Current Opinion in Neurology 27(4): 468-476.

2. Carter Kevin A, Hathaway, Nathanael E, Lettieri Christine F (2014) Common sleep disorders in children. American Family Physician 89 (5): 368-377.

3. Machado Eduardo, Dal-Fabbro Cibele, Cunali, Paulo Afonso, Kaizer Osvaldo Bazzan (2014) Prevalence of sleep bruxism in children: A systematic review. Dental Press Journal of Orthodontics 19(6): 54-61.

4. Gradisar Michael, Gardner Greg, Dohnt Hayley (2011) Recent worldwide sleep patterns and problems during adolescence: A review and metaanalysis of age, region, and sleep". Sleep Medicine 12(2): 110-118.

5. Heinimaa, Markus (2002) Incomprehensibility: The role of the concept in DSM-IV definition of schizophrenic delusions". Medicine, Health Care and Philosophy 5(3): 291-295.

6. Pierre, Joseph M (2001) "Faith or Delusion? At the Crossroads of Religion and Psychosis". Journal of Psychiatric Practice. 7 (3): 163-172.

7. Johnson CV, Friedman HL (2008) Enlightened or Delusional: Differentiating Religious, Spiritual, and Transpersonal Experiences from Psychopathology. Journal of Humanistic Psychology 48(4): 505-527.

8. Siddle R, Haddock G, Tarrier N, Faragher EB (2002) Religious delusions in patients admitted to hospital with schizophrenia. Social Psychiatry and Psychiatric Epidemiology 37(3): 130-138.

9. Mohr S, Borras L, Rieben I, Betrisey C, Gillieron C, et al. (2009) Evolution of spirituality and religiousness in chronic schizophrenia or schizoaffective disorders: a 3-years follow-up study". Social Psychiatry and Psychiatric Epidemiology 45(11): 1095-1103.

10. Hardeland R, Pandi-Perumal SR, Cardinali DP (2006) Melatonin. The International Journal of Biochemistry \& Cell Biology 38 (3): 313-316.

11. Tan DX, Hardeland R, Manchester LC, Korkmaz A, Ma S, et al. (2012) Functional roles of melatonin in plants, and perspectives in nutritional and agricultural science. Journal of Experimental Botany 63(2): 577597.

12. Altun A, Ugur-Altun B (2007) Melatonin: therapeutic and clinical utilization. Int J Clin Pract 61(5): 835-845.

13. Boutin JA, Audinot V, Ferry G, Delagrange P (2005) Molecular tools to study melatonin pathways and actions. Trends Pharmacol Sci 26 (8): 412-419.

14. Hardeland R (2005) Antioxidative protection by melatonin: multiplicity of mechanisms from radical detoxification to radical avoidance. Endocrine 27(2): 119-130.

15. Reiter RJ, Acuña-Castroviejo D, Tan DX, Burkhardt S (June 2001) Free radical-mediated molecular damage. Mechanisms for the protective actions of melatonin in the central nervous system. Ann NY Acad Sci 939: 200-215.

16. Brent Bauer MD (2011) Melatonin side effects: What are the risks? Mayo Clinic.

17. Zhdanova IV, Wurtman RJ, Regan MM, Taylor JA, Shi JP, et al. (2001) Melatonin treatment for age-related insomnia. J. Clin Endocrinol Metab 86(10): 4727-4730.

18. Morera AL, Henry M, de La Varga M (2001) Seguridad en el uso de la melatonina [Safety in melatonin use]. Actas Esp Psiquiatr (in Spanish) 29(5): 334-337.

19. Terry PD, Villinger F, Bubenik GA, Sitaraman SV (2009) Melatonin and ulcerative colitis: evidence, biological mechanisms, and future research. Inflamm. Bowel Dis 15(1): 134-140.

20. Juszczak M, Michalska M (2006) Wpływ melatoniny na syntezę i wydzielanie prolaktyny, hormonu luteinizującego (LH)i 
folikulotropowego (FSH)" [The effect of melatonin on prolactin, luteinizing hormone ( $\mathrm{LH})$, and follicle-stimulating hormone (FSH) synthesis and secretion]. Postepy Hig Med Dosw (Online) (in Polish) 60: 431-438.

21. Srinivasan V, Spence WD, Pandi-Perumal SR, Zakharia R, Bhatnagar KP (2009) Melatonin and human reproduction: shedding light on the darkness hormone. Gynecol Endocrinol 25(12): 779-785.
22. Lebish IJ and Moraski RM (1987) Mechanisms of immunomodulation by drugs. Toxicol Pathol 15(3): 338-345.

23. Voderholzer Ulrich, Guilleminault Christian (2012) "Sleep disorders". Neurobiology of Psychiatric Disorders. Handbook of Clinical Neurology 106: 527-540. 